Journal of Thermal Engineering, Vol. 7, No. 4, pp. 715-730, May, 2021

Yildiz Technical University Press, Istanbul, Turkey

\title{
THERMAL PERFORMANCE INVESTIGATION OF A HYBRID SOLAR AIR HEATER APPLIED IN A SOLAR DRYER USING THERMODYNAMIC MODELING
}

\author{
Ali Heydari ${ }^{*}$, Mikaeil Forati², Seyyed Mahan Khatam³
}

\begin{abstract}
Hybrid air heater is a device taking advantage of two or more energy sources directly or indirectly for heating air. This study aims to analyze energy and exergy for a hybrid air heater. It is assumed that no thermal gradient exists along glass thickness and one-directional variation of temperature is in flow direction and thermal capacity of glass, absorber plate, and thermal insulations are negligible. To avoid food oxidation in dryers, effects of heating fluid such as air, carbon dioxide, and nitrogen on temperature, heat transfer, and thermodynamic first and second law efficiencies are also investigated along with the effects of hybrid heating on the aforementioned parameters. The problem is solved using MATLAB software and invoking iterative method with convergence criterion of 0.0001 for temperature. Results indicate the positive effects of using carbon dioxide. Applying hybrid system is also shown to increase the efficiency of air heater.
\end{abstract}

Keywords: Exergy, Hybrid air heater, Fluid properties, Efficiency

\section{INTRODUCTION}

Solar energy is among the most important renewable energy sources on Earth which is not only compatible with environment, but also it is always available in the large part of Earth's surface and human beings have always tried to harness this energy and utilize it optimally. Today, solar energy has the wide range of applications such as supply of hot water for urban and rural consumption, air-conditioning in constructions, and particularly dehydration of agricultural products, electricity generation in power plant with solar collectors, etc. Application of various types of solar collectors is one of the methods for harnessing solar energy. Production and maintenance of solar air collectors are simple. Corrosion of air passage, air leakage, conductivity of absorber plate, and freezing of fluid do not pose problems in air collectors and they are considered as the advantages of this kind of collectors over solar collectors in which water is used as the working fluid. Advantages of hybrid air heater include:

Hybrid system is usable in cloudy days and in the absence of sun.

Consumption of fossil fuels or electricity is reduced to minimum.

Less pollution is produced due to application of solar energy.

Among the conducted studies on solar air heater, one can mention the work of Forson et al.[1]. In this study, two models for a single pass, double duct solar air heater were investigated and compared and the obtained results were measured against each other. The results revealed the effects of collector number and mass flow rate and relative humidity. In 2008, Aharwal et al. [2]studied the thermal performance of air heater by considering various parameters like length to thickness ratio, angle, gap position, and surface roughness parameter. In this study, the maximum heat transfer was observed in Nusselt number of 2.59 and 2.87.

This paper was recommended for publication in revised form by Regional Editor Mustafa Kilic

${ }^{I}$ Department of Mechanical Engineering, University of Torbat Heydarieh, Torbat Heydarieh, Khorasan Razavi, Iran

${ }^{2}$ Young Researchers and Elite Club, Semnan Branch, Islamic Azad University, Semnan, Iran

${ }^{3}$ Department of Materials and Environmental Technology, Tallinn University of Technology, Ehitajate tee 5, 19086 Tallinn, Estonia

*Email Address: a.heydary@torbath.ac.ir

Orcid ld: 0000-0002-4563-2648, 0000-0001-9766-7829, 0000-0002-5377-5235,

Manuscript Received 28 May 2019, Accepted 21 August 2019 
Saxena et al. [3] evaluated the thermal performance of air heater by studying active solar air heater. In this work, temperature inside air heater and thermal performance were enhanced by applying two halogen lights of 300 W. The results included enhancement of thermal efficiencies by $18.04 \%$ to $20.78 \%$ in compared with natural convection and by $52.21 \% 80.05 \%$ in compared with forced convection.

The focus in the study conducted by Singh et al. [4] was placed on obtaining heat in different times. Temperatures were calculated from 9 AM to 6 PM and study was carried out on a solar air heater packed with stone. In this research, it was proved that using this type of air heater is highly suitable due to its heat storage. Temperature in the bed packed with stone is directly related to output temperature of air flow.

In addition to experimental and laboratorial researches, many studies for numerical modeling as well as analytical researches have been conducted. Work of Choudhury et al. [5] is considered as the first studied on air heaters. They investigated two types of air heaters with absorber glass in 1996. In this research, behavior and efficiency of air heater were observed by changing flow rate, glass thickness, length and depth of duct.

Garg and Adhikari [6] investigated the efficiency, temperature of output flow, flow rate, and number of solar cells in single-glass and double-glass air heaters and provided the optimum air heater based on thermal efficiency and heater cost.

Gawande et al. [7] in 2016 conducted numerical and experimental studies on roughened solar air heater and reviewed the effect of angle and direction of ribs on heat transfer from air heaters. The results of this study revealed the optimum angle and length in air heaters. Jin et al. [8] evaluated the heat transfer by CFD software after applying ribs inside the duct of air heater. In this research, effects of various parameters such as surface roughness and Reynolds number were discussed on heat transfer and $R N G, K-\varepsilon, K-\omega$ models were utilized for conducting simulation.

As hybrid investigations, Amori and Abd-AlRaheem [9] studied the thermal performance of photovoltaic/thermal hybrid collectors for Iraq climate and discussed their thermal efficiency and output temperature. In addition to the conducted studies, other researches have also been carried out for reviewing the thermal performance and optimization of hybrid systems [10-13]. Manzolini et al. [14] studied the performance enhancement of air heater supported by heat pump. In this study, fluid dynamic analysis was conducted. Gawande et al. [15] performed a modeling for demonstrating the effect of air heater accompanied by heat storage system. In 2017, Fan et al.[16] investigated a dynamic model for air heater with fins and revealed the positive effect of using fins on performance enhancement.

For the purpose of drying systems, Hakim et al. [17] recently investigated experimentally the application of heat pipe on low enthalpy geothermal energy utilization for agricultural products dryers. They showed that the smallest and the biggest effectiveness related to this system is $23.7 \%$ and $61.4 \%$ respectively. In another work, Heydari and Mesgarpour [18] perform an experimental and numerical study of solar air heater with helical flow path. They used air, $\mathrm{Co} 2$ and $\mathrm{N} 2$ as the working fluid for drying purpose. They showed that in a solar air heater with helical flow path one can use nitrogen rather than air to maintain quality of the product while achieving the same heat exchange performance. To improve the performance of solar air heaters for drying applications Raj et al. [19] presented a costeffective method using discrete macro-encapsulated PCM capsules. They showed that an average encapsulate efficiency of $47.2 \%$ and $67 \%$ was obtained for double-pass solar air heater system equipped with rectangular and cylindrical macro-encapsulates respectively. Sreekumar [20] performed a techno-economic analysis of a roofintegrated solar air heating system for drying fruit and vegetables. He showed that the cost of drying $1 \mathrm{~kg}$ pineapple with this system was roughly half of that of an electric dryer. Yıldırım and Özdil [21] theoretically investigated a solar air heater which roughened by ribs and grooves. They examined ratio of the relative roughness height, relative roughness pitch, and groove positions to pitch (GP/PR) for Reynolds number range from 3000 to 21,000. In an experimental investigation Singh et al. [22] studied the effect of triangular protrusions as roughness geometry on 
thermo hydraulic performance of solar air heater. Their results conducted an increase in heat transfer and pressure drop in solar air heater due to roughened absorber plate.

As a summary of experimental, numerical and analytical works performed in the field of air heaters, the effect of various variables has been investigated on the performance of air heaters such as number of collectors, mass flow inlet, angle of positioning, gap, length to thickness ratio, roughness, flow path, etc. In some other works, researchers tried to increase their thermal performance with changes in absorber plate (porous media, phase change material, etc.) or glass layer (single or two layers, absorber glass, glass thickness, etc.). Addition of auxiliary heat source is another way to increase thermal performance but with high primitive cost.

In the present study, assuming that an auxiliary heating system is added to air heater, thermodynamic analysis is performed and effects of different powers of auxiliary system on thermal performance of air heater are discussed. Moreover, provided that the hybrid air heater is used as energy supplier of a food dehydrator, heated inert gases such as nitrogen or carbon dioxide can also be substituted for air to prevent food oxidization. Therefore, effect of heated gas on thermal performance of air heater is also considered in the present study. The novelty of this research can be explained in two ways :

1) Exergy analysis for a thermal air heater with auxiliary heat source.

2) Evaluation of thermal performance of the heater using inactive gases instead of air in the drying process.

\section{GOVERNING EQUATIONS}

\section{Thermodynamic analysis}

The heater operates in the way that the radiation emitted by the sun passes through a glass plate and is absorbed by an absorber plate. The fluid flow streaming above the absorber plate is heated along its length.

Energy of flow is calculated by thermal balance equation. The following assumptions are also made for simplifying and solving governing equations:

1. Thermal capacity of glass, absorber plate, and thermal insulations are assumed to be negligible.

2. There is no air leakage.

3. Flow temperature varies only in streamwise direction.

4. There is no thermal gradient along glass thickness.

5. The heat produced by auxiliary system is entirely transferred to the absorber plate.

A schematic of the system which is analyzed in this paper is illustrated in Fig. 1.

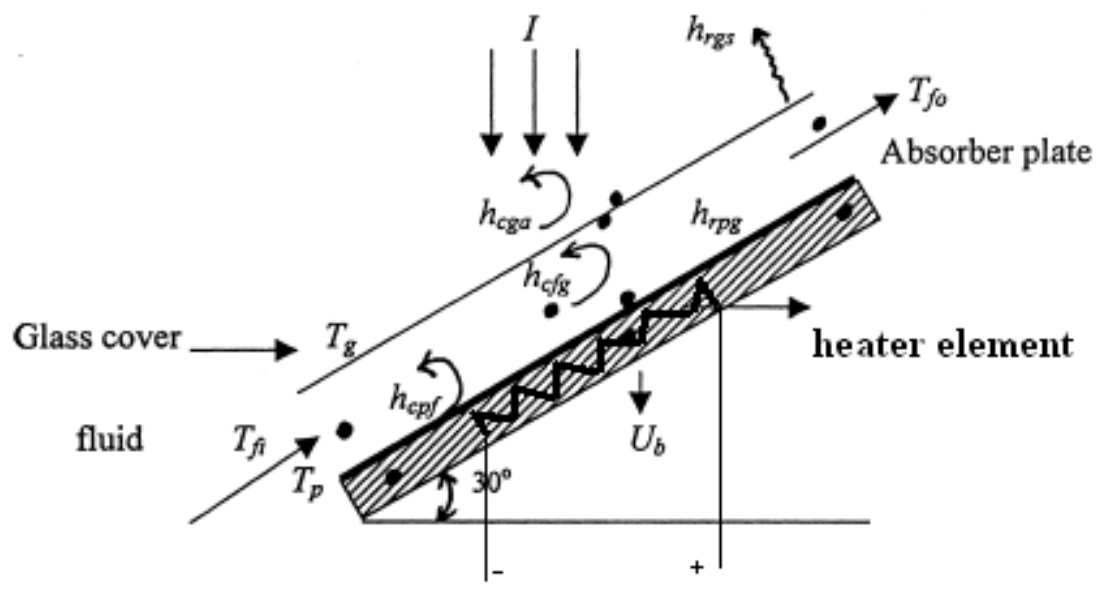

Figure 1. Schematic of analyzed hybrid heater 
Journal of Thermal Engineering, Research Article, Vol. 7, No. 4, pp. 715-730, May, 2021

\section{Energy conservation for glass covering}

Heat transfer equation for glass surface reads [26]:

$$
I(t) \alpha_{g}+h_{r b g}\left(T_{b}-T_{g}\right)+h_{r b g}\left(T_{f}-T_{g}\right)=h_{r g s}\left(T_{g}-T_{s}\right)+h_{r g a}\left(T_{g}-T_{a}\right)
$$

The above equation provides the temperature of glass surface as [26]:

$$
T_{g}=\frac{I(t) \alpha_{g}+h_{r b g}\left(T_{b}-T_{g}\right)+h_{r b g}\left(T_{f}-T_{g}\right)}{h_{r b g}+h_{r b}+h_{r g s}+h_{r g a}}
$$

\section{Energy conservation for absorber plate}

Heat transfer equation for absorber surface is as follows:

$$
I(t) \tau_{b} \alpha_{b}+w a t t=h_{c b f}\left(T_{b}-T_{f}\right)+h_{r b g}\left(T_{b}-T_{g}\right)+U_{b}\left(T_{b}-T_{a}\right)
$$

The temperature of absorber surface is also given by the following equation as:

$$
T_{b}=\frac{I(t) \tau_{b} \alpha_{b}+w a t t+h_{c b f} T_{f}+h_{r b g} T_{g}+U_{b} T_{a}}{h_{c b f}+h_{r b g}+U_{b}}
$$

\section{Energy conservation for air flow}

By writing heat transfer equation for air flow, we have [26]:

$$
h_{c b f}\left(T_{b}-T_{f}\right)=h_{c g f}\left(T_{f}-T_{g}\right)+\frac{\dot{m} C_{p}}{b} \frac{d T_{f}}{d y}
$$

Finally, the following equation is derived by solving and integrating the above equation [26]:

$$
T_{f}=\frac{A}{B_{b}}+\left(\frac{C\left(A-B_{b} T_{i}\right)}{L B_{b}{ }^{2}}\right)\left(\exp \left(\frac{-B_{b} L}{C}\right)-1\right)
$$

In which coefficients $\mathrm{A}, \mathrm{B}$, and $\mathrm{C}$ are obtained by the following relations:

$$
\begin{gathered}
A=h_{c b f} T_{b}+h_{c f g} T_{g} \\
B=h_{c f g}+h_{c b f} \\
C=\dot{m} C_{p} / b
\end{gathered}
$$

Conductivity and emissivity are also given as[23]

$$
\begin{gathered}
h_{r b g}=\varepsilon \sigma\left(T_{b}^{2}+T_{g}^{2}\right)\left(T_{b}+T_{g}\right) \\
\varepsilon=\frac{1}{1 / \varepsilon_{t}+1 / \varepsilon_{g}-1} \\
h_{c g a}=2.8+3 V
\end{gathered}
$$

Parameters $h_{c g f}$ and $h_{c b g}$ are also obtained as follows invoking the definition of Nusselt number on the surface of absorber and glass[23]:

$$
N u=1+1.44[1-(1708 / R a \cos \theta)]^{+}+\left[(R a \cos \theta / 5830)^{1 / 3}-1\right]^{+}
$$


Nusselt number in Eq. (13) is obtained for a specific $R a$ by considering $\theta=\pi / 6$ :

$$
h=\frac{N u k_{f}}{d}
$$

Rayleigh number in Eq. (13) is also calculated by the following formula:

$$
R a=\frac{g \beta\left(T_{b}-T_{f}\right) D^{3}}{\alpha \vartheta}
$$

\section{Efficiency calculations}

First law efficiency can be generally regarded as the ratio of the desired output to the required input. First law efficiency cannot solely be considered as an actual criterion for system performance. In order to address this problem, second law efficiency has been defined which is criterion for measuring the actual performance of system against its best performance under the same conditions. For heat engines, second law efficiency is defined as the ratio of the actual thermal efficiency to the maximum possible thermal efficiency (reversible) in the same conditions.

Given the thermodynamic first law, thermal efficiency of hybrid air heater is calculated as:

$$
\eta_{t h}=\frac{m c_{p}\left(T_{f o}-T_{i}\right)}{I_{t} A_{c}+w a t t}
$$

Analysis of second thermodynamic law requires calculating input and output exergy from system. Exergy of fluid flow passing through collector surface is outlined as output exergy in the following form[24]:

$$
E x_{n}=m c_{p}\left(T_{f o}-T_{i}\right)-m c_{p} T_{f o} \log \left(\frac{T_{f o}}{T_{i}}\right)+m R T_{f o} \log \left(\frac{P_{0}-\Delta P}{P_{0}}\right)
$$

In the above equation, the right hand side term denotes the absorbed exergy by air flow. The second and third terms also indicate exergy loss. Therefore, exergy efficiency is derived as follows:

$$
\eta_{\text {ex }}=\frac{E x_{n}}{E x_{s}+E x_{\text {elem }}}
$$

In which exergy of sun radiation is calculated as follows[25]:

$$
E x_{s}=I_{t} A_{c}\left(1-\frac{T_{a}}{T_{\text {sun }}}\right)
$$

$T_{\text {sun }}=5778 \mathrm{~K}$ is assumed for solving above equation. Ex $x_{\text {elem }}$ is the exergy of element which is also considered equal to its consuming power

\section{The Problem conditions:}

The considered air heater in this study is single-duct air heater. MATLAB software is used for solving this problem. To investigate the effect of fluid flow rate and element power, they are changed from $0.00117 \mathrm{~kg} / \mathrm{s}$ to 0.01017 $\mathrm{kg} / \mathrm{s}$ and 0 to $1000 \mathrm{~W}$ respectively. During these changes the radiation intensity is fixed at $400 \mathrm{~W} / \mathrm{m}^{2}$ and the ambient (inlet) temperature is equal to $298 \mathrm{~K}$. The lower surface of absorber plate is insulated and the thermal condition of glass is combined of convection and radiation simultaneously. A heat generation from the element has been added to the absorber plate. The considered environmental conditions and dimensions in solving the problem are shown in Table 1. Air, nitrogen and carbon dioxide are also used as working fluid whose properties are listed in Table 2 [27]. 
Journal of Thermal Engineering, Research Article, Vol. 7, No. 4, pp. 715-730, May, 2021

Table 1. The considered dimensions and environmental conditions of the problem

\begin{tabular}{|c|r|c|c|}
\hline Parameter & Values & Parameter & Values \\
\hline $\begin{array}{c}\text { Thermal conduction coefficien } \\
\text { insulation }\end{array}$ & $0.038 \mathrm{~W} /$ & Fluid flow rate & $0.00117-0.01017 \mathrm{~kg} / \mathrm{s}$ \\
\hline \multirow{2}{*}{ Angle of air heater } & $30^{\circ}$ & Radiation intensity & $400 \frac{\mathrm{W}}{\mathrm{m}^{2}}$ \\
\cline { 3 - 4 } & $5 \mathrm{~cm}$ & width of air heater & $1 \mathrm{~m}$ \\
\hline Gap between glass and absor & $1 \mathrm{~m}$ & Element temperature & $298 \mathrm{~K}$ \\
\hline Length of air heater & 0.9 & Emissivity of absorber pl & $0-1000 \mathrm{watt}$ \\
\hline Emissivity of glass cover & 0.05 & Absorptivity of absorber $p$ & 0.95 \\
\hline Absorptivity of glass cover & 0.9 & Thickness of the insulati & 0.9 \\
\hline Transmissivity of glass cove & & & $5 \mathrm{~cm}$ \\
\hline
\end{tabular}

Table 2. Properties of the working fluids [27]

\begin{tabular}{|c|c|c|c|c|c|c|}
\hline Fluid & $\begin{array}{l}\text { Densit } \\
\frac{\boldsymbol{k g}}{\boldsymbol{m}^{3}}\end{array}$ & $\begin{array}{l}\begin{array}{l}\text { Viscosity } \\
\text { kg. } \mathbf{m}^{2}\end{array} \\
\boldsymbol{s}\end{array}$ & $\begin{array}{l}\text { Specific Heat } \\
\text { Capacity } \\
\frac{\boldsymbol{j}}{\boldsymbol{k g ~ K}}\end{array}$ & $\begin{array}{l}\text { Gas Constan } \\
\frac{\boldsymbol{j}}{\boldsymbol{k g} \mathbf{K}}\end{array}$ & $\begin{array}{l}\text { Thermal Conducti } \\
\qquad \frac{\boldsymbol{w}}{\boldsymbol{m} \boldsymbol{K}}\end{array}$ & $\begin{array}{l}\text { Thermal Diffusi } \\
\qquad \frac{\boldsymbol{m}^{2}}{\boldsymbol{s}}\end{array}$ \\
\hline Air & 1.225 & $18.11 * 10^{-6}$ & 1014 & 287 & 0.02587 & $2.343 * 10^{-6}$ \\
\hline Carbon Dio & 1.842 & $1.49 * 10^{-5}$ & 843 & 188.9 & 0.01624 & $5.141 * 10^{-6}$ \\
\hline Nitroger & 1.138 & $1.663 * 10^{-5}$ & 1039 & 296.8 & 0.0247 & $2.494 * 10^{-5}$ \\
\hline
\end{tabular}

\section{VALIDATION}

In this study, thermodynamic modeling and evaluation of a hybrid air heater are conducted. Since validation is highly important in every numerical analysis or thermodynamic modeling, this point is taken into account in the following. In this regard, study of Aboul-Enein et al. [26] is taken as the base of comparison. The condition that was modeled to compare with Aboul-Enein et al. [26] is demonstrated in table 3. The results of this reference are calculated in 17 July, 1996 which diurnal variations of solar intensity and ambient temperature is illustrated in figure 2.

Table 3. Comparison conditions for Validation the results with Aboul-Enein et al. [26]

\begin{tabular}{|c|c|}
\hline Parameter & Values \\
\hline Inlet velocity & $3 \mathrm{~m} / \mathrm{s}$ \\
\hline Angle of air heater & $30^{\circ}$ \\
\hline $\begin{array}{c}\text { Gap between glass and } \\
\text { absorber }\end{array}$ & $5 \mathrm{~cm}$ \\
\hline Length of air heater & $1 \mathrm{~m}$ \\
\hline width of air heater & $1 \mathrm{~m}$ \\
\hline Fluid flow rate & $0.00117 \mathrm{~m} / \mathrm{s}$ \\
\hline
\end{tabular}


Journal of Thermal Engineering, Research Article, Vol. 7, No. 4, pp. 715-730, May, 2021

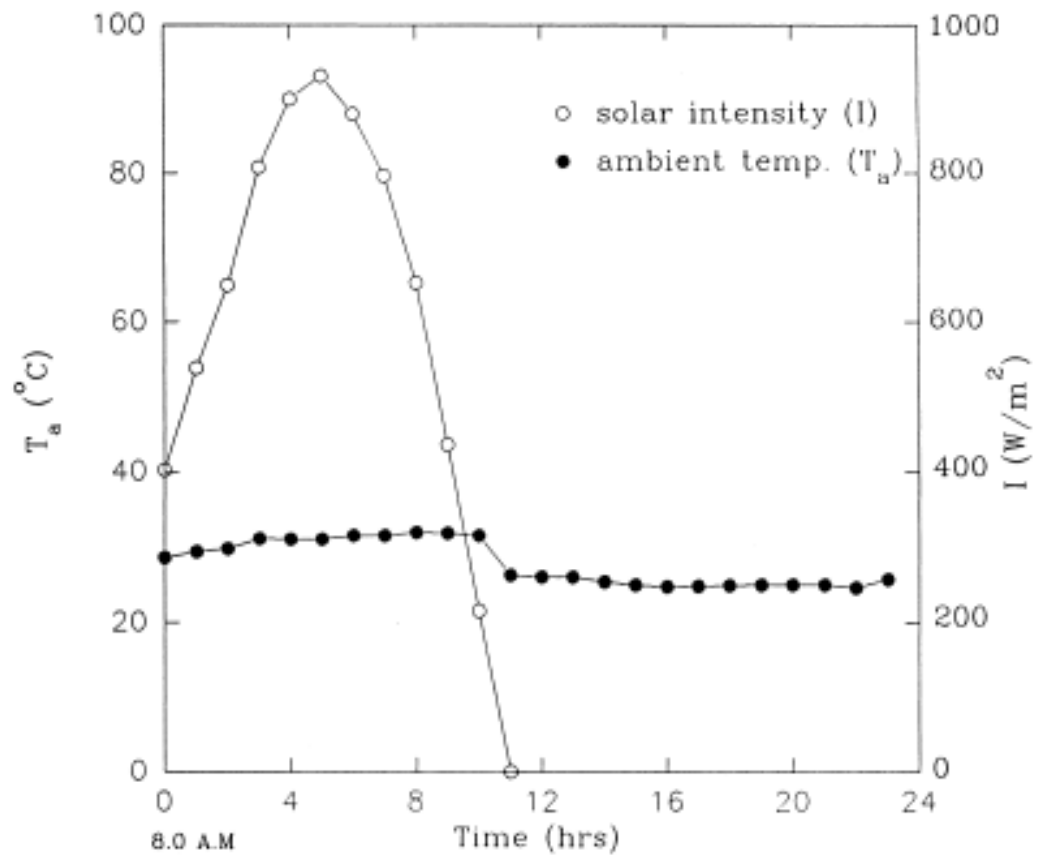

Figure 2. Diurnal variations of solar intensity and ambient temperature in 17 July, 1996 [26]

Figure 3 shows validation and correctness of problem solution. It is worth mentioning that results contain the maximum error of $4.43 \%$ and minimum error of $0.46 \%$ in compared with those of Aboul-Enein et al. [26].

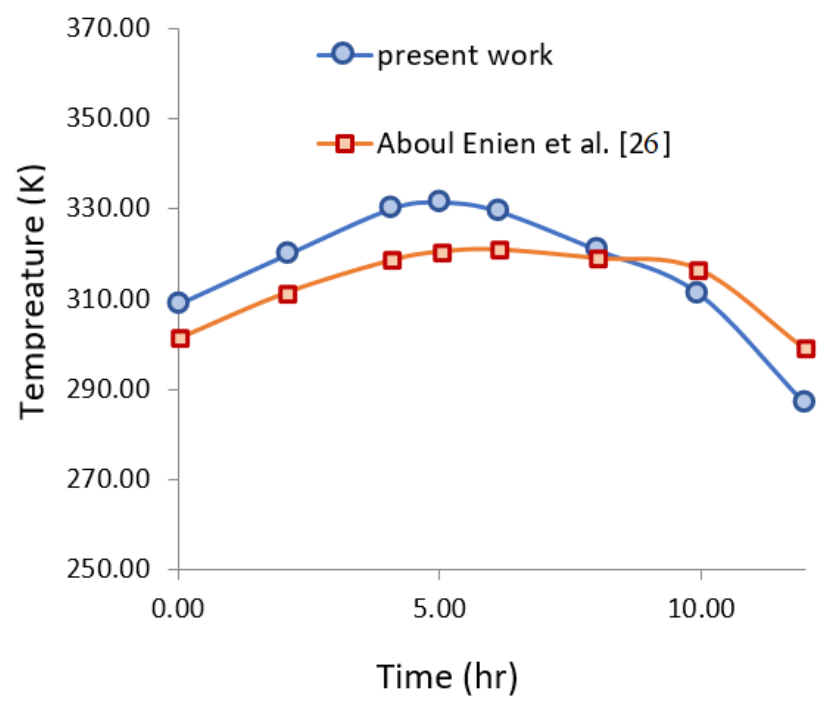

Figure 3. The results of comparison between this study and Aboul-Enein et al. [26]

\section{ALGORITHM PRESENTATION}

Given the importance of solution method, the presented algorithm in MATLAB software for solving problem is discussed in this section.

To solve the problem, iterative algorithm with convergence criterion of 0.0001 for temperature is considered. Software firstly reads the preliminary data of velocity, temperature, flow rate, problem dimensions, thermal radiation 
of sun, specific thermal capacity, and absorption coefficients, etc. as input data, and then, by calculating dimensionless numbers of Rayleigh, Nusselt, and thermal conduction coefficients, it starts conditional loop and energy analysis for different components of air heater and after calculating temperatures, conditional loop continues until termination criterion of 0.001 is satisfied. Temperatures are reported in output after loop is terminated and then thermal and exergy efficiencies are reported as the ultimate output. A brief illustration of the problem flowchart is shown in figure 4 .

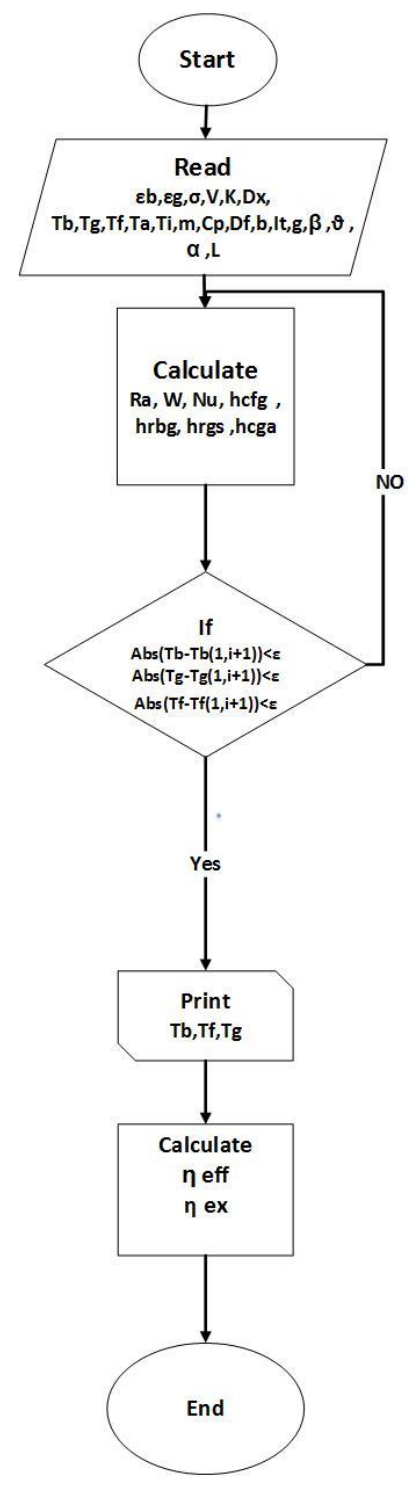

Figure 4. Flowchart of procedures

\section{RESULTS AND DISCUSSION}

After validating the obtained results, the effects of different variables on performance of solar air heater are investigated. In this section, the effect of changing auxiliary power caused by thermal element is discussed in the constant flow rate of 0.01017 kilogram per second. In addition, performance of air heater is evaluated in different flow rates in two cases without element and in the presence of 600-watt generated power. It should be noted that all of calculations for the three flown gasses, including air, nitrogen, and carbon dioxide in air heater are checked. Since one of the applications of solar air heaters is in food dehydrators, nitrogen and carbon dioxide are selected as working fluids and their performance is compared with that of air. Because they are neutral gas, and so in the absence of 
oxygen, oxidization and quality reduction do not occur in dehydrator. In addition, these gases are more economical than other neutral gases.

\section{Effect of auxiliary input power}

In figure 5, the effect of changing secondary power caused by thermal element on output temperature from air heater is shown in the constant flow rate of 0.01017 kilogram per second for three working fluids of air, nitrogen, and carbon dioxide. As it is expected, enhancement in the power of element increases output temperature of working fluid. But the most important result is that output temperatures for nitrogen and carbon dioxide are more than that of air. Output temperatures of nitrogen and carbon dioxide get close in low input power while the output temperature of carbon dioxide exceeds that of nitrogen when auxiliary power increases. The effective parameters on this behavior include physical properties of working fluids such as conduction coefficient, specific thermal capacity, density, thermal diffusivity, viscosity, and gas constant.

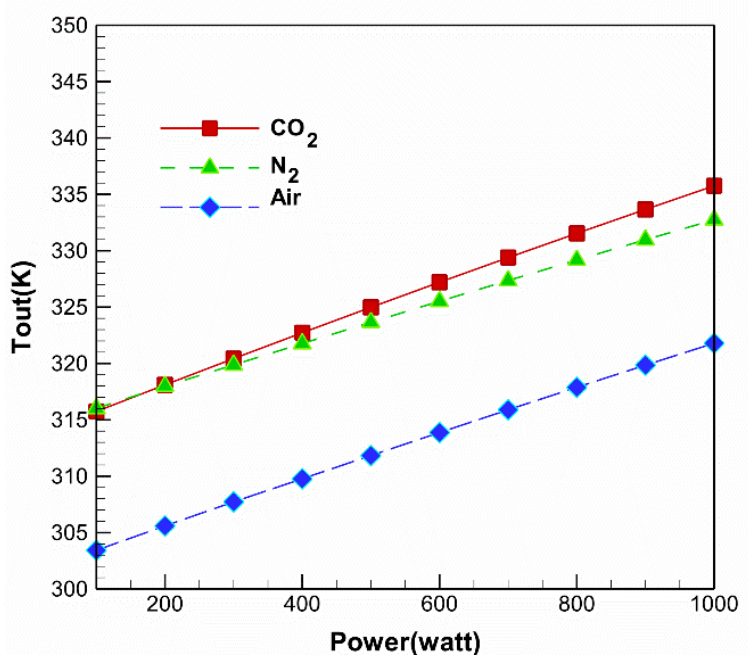

Figure 5. Variation of output temperature with auxiliary power in constant mass flow rate for different gases

The effect of changing secondary power due to thermal element on thermal efficiency of air heater is presented in figure 6 for three working fluids of air, nitrogen, and carbon dioxide and in the constant flow rate of 0.01017 kilogram per second. As it is seen, because increase in the power of element makes increase in the temperature gradient between input and output of air heater, efficiency is enhanced due to Eq. (16). On the other hand, power of element is placed in the denominator of this equation and it is added to sun radiation which leads to less variation in efficiency in compared with when it were alone in denominator. Therefore, the extent of increase in nominator is much more than denominator and efficiency is enhanced by increasing element power. Moreover, it is obvious that the maximum thermal efficiency is associated with air and the minimum is related to nitrogen. Also, it is seen that increasing slope of efficiency in lower powers is much steeper than that of higher powers. 


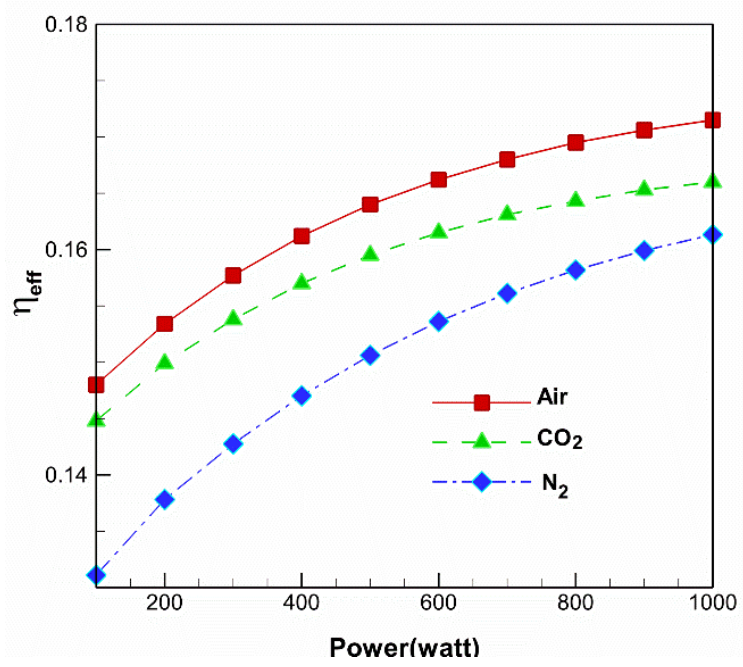

Figure 6. Variation of thermal efficiency with auxiliary power in constant mass flow rate for different gases

Variation of second law efficiency against element power in constant flow rate is shown in figure 7. As it is shown, increase of element power enhances second law efficiency with constant slope. It is also evident that more second law efficiency is obtained in hybrid air heater when carbon dioxide is applied rather than air and nitrogen. While variation of second law efficiency with auxiliary power for air and nitrogen are quite the same.

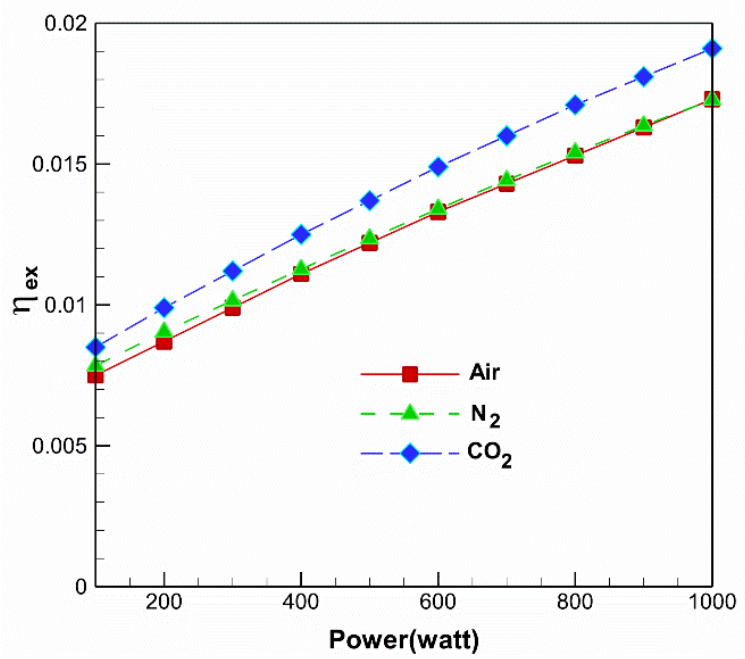

Figure 7. Variation of Exergic efficiency with auxiliary power in constant mass flow rate for different gases

\section{Effect of mass flow rate without auxiliary power}

In this section, effect of changing flow rate of three working fluids in air heater is considered on the performance of solar air heater supplying energy only by sun radiation in the absence of thermal element. As it is seen in figure 8, increase in flow rate decreases output temperature as it reduces the heat transfer time between fluid and absorber plate. In these conditions, behavior of output temperature under variation of flow rate is similar for carbon dioxide and nitrogen gases. Decreasing slope for output temperature of air is also less than that of nitrogen and carbon dioxide. 


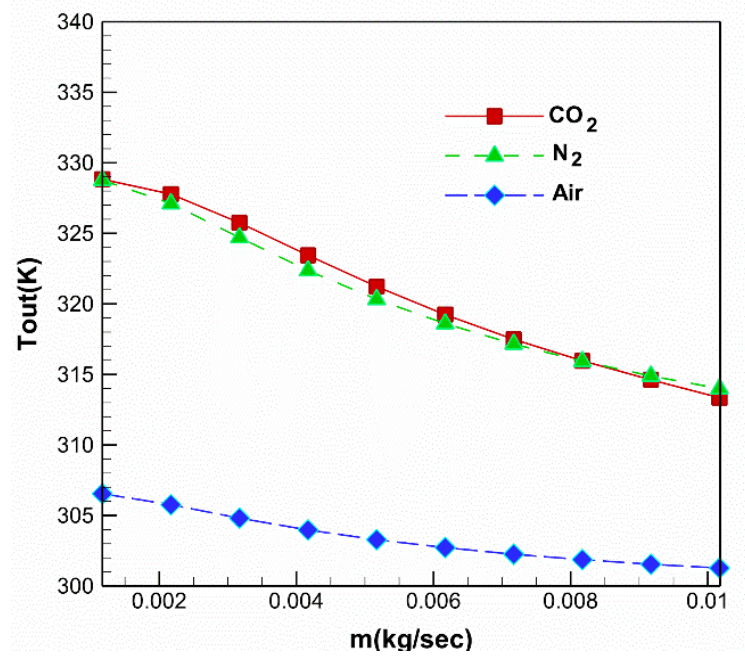

Figure 8. Variation of output temperature with mass flow rate in watt $=0$ for different gases

According to figure 9, by increase of flow rate, thermal efficiency is enhanced by steep slope at first and then followed by gentle slope. That is emanated from the fact that in calculating thermal efficiency, increase of flow rate dominates the reduction of the temperature gradient between input and output of air heater. Like Fig. 5, the maximum thermal efficiency of air heater is associated here with working fluid of air while its minimum is related to air heater working with nitrogen. However, the increasing slope of efficiency versus flow rate is steeper for air heater with working fluid of carbon dioxide than others.

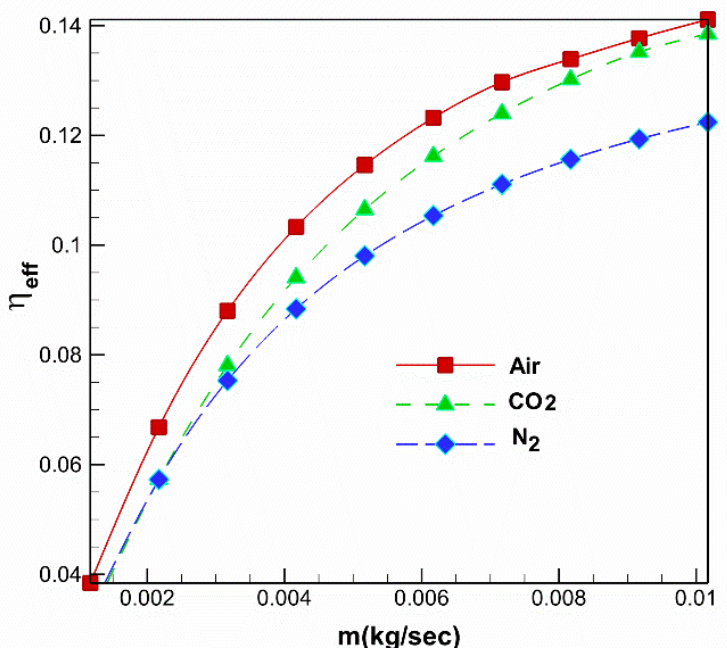

Figure 9. Variation of thermal efficiency with mass flow rate in watt $=0$ for different gases

Variation of second law efficiency with changing flow rate of fluid in air heater without thermal element is shown in figure 10. As it is seen in the figure, when flow rate increases, second law efficiency firstly increases and reaches its highest value in a point and then decreases. The maximum second law efficiency is obtainable for air heater with working fluid of carbon dioxide in higher flow rates. The maximum second law efficiency for air is obtained in lower flow rates in compared with other gases. It is also observed that second law efficiency has its highest value for air and its minimum for nitrogen in lower flow rates. In higher flow rates, however, the maximum and minimum second law efficiency is related to carbon dioxide and air, respectively. 


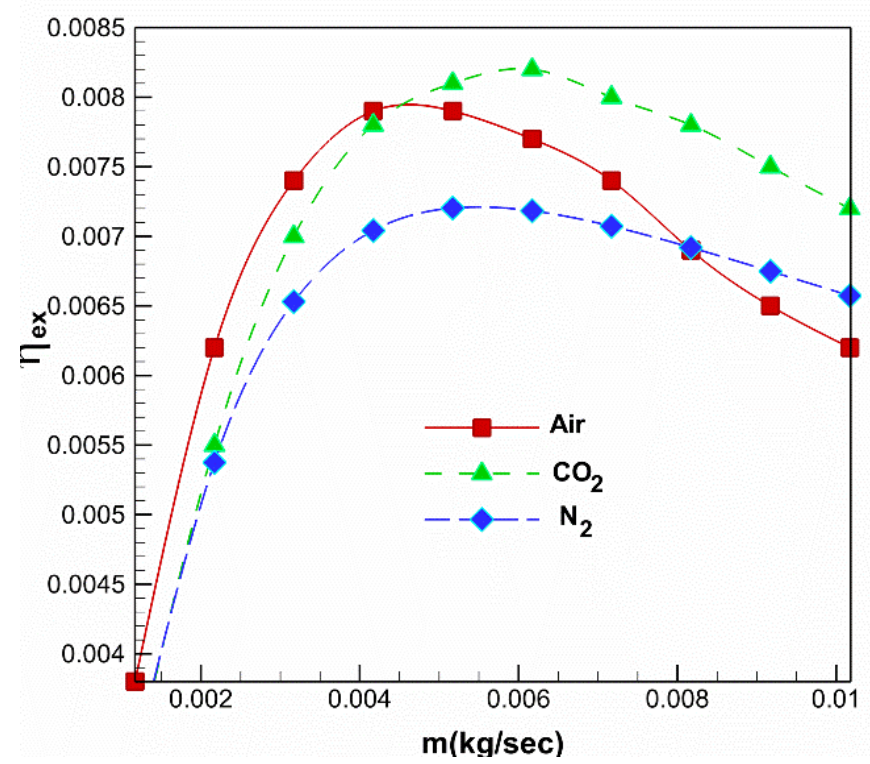

Figure 10. Variation of exergic efficiency with mass flow rate in watt $=0$ for different gases

\section{Effect of mass flow rate with auxiliary power}

In this section, effect of flow rate is investigated when power of element is added to air heater in hybrid mode. Figure 11 demonstrates the effect of flow rate on output temperature of air heater in the presence of thermal element. Comparing with figure 8 , it is evident that variation of output temperature with changing flow rate for nitrogen is different from that of carbon dioxide and they are not in agreement anymore. This means that effects of nitrogen and carbon dioxide in hybrid air heater (unlike solar air heater) are different. The variation of output temperature with changing air flow rate has also steeper slope in hybrid mode than solar mode.

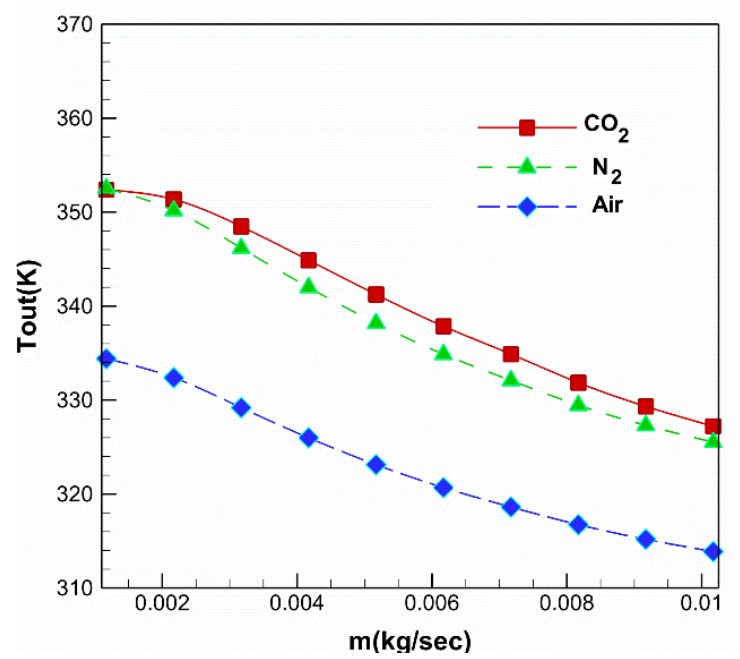

Figure 11. Varation of output temperature with mass flow rate in watt $=600$ for different gases

Effect of flow rate on thermal efficiency of air heater in hybrid mode with 600-watt element power is studied in figure 12. Comparing this figure with Fig. 8, it is seen that when air heater is in hybrid mode, air heater efficiency in lower flow rates is more for nitrogen than carbon dioxide, however, as flow rate increases, efficiency of air heater 
with carbon dioxide exceeds that of nitrogen; this is while, in solar air heater (figure 9) thermal efficiency of system working with carbon dioxide is always more than nitrogen in all flow rates.

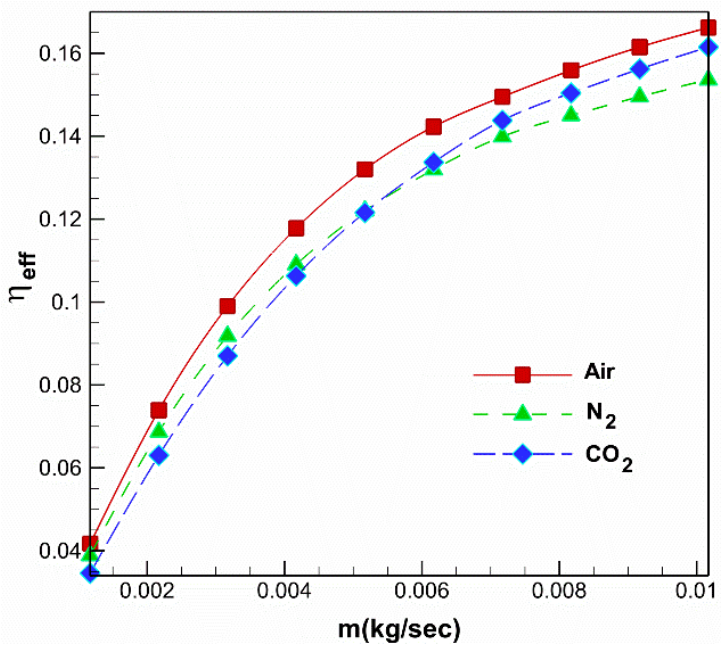

Figure 12. Variation of efficiency with mass flow rate in watt $=600$ for different gases

Figure 13 evaluates the effect of flow rate on second law efficiency in hybrid mode in the presence of 600watt element power. Comparing this figure with figure 10, it is shown that in higher flow rates, behavior of second law efficiency for air heater working with air is similar to nitrogen. The maximum second law efficiency is also achieved in higher flow rates as air heater switches to hybrid mode. Considering the aforementioned results, carbon dioxide is the best working fluid in air heater used in dehydrators because it is neutral gas with which food product does not oxidize. Furthermore, it is characterized by more output temperature and second law efficiency in compared with other discussed fluids. Moreover, it is much more economical than nitrogen.

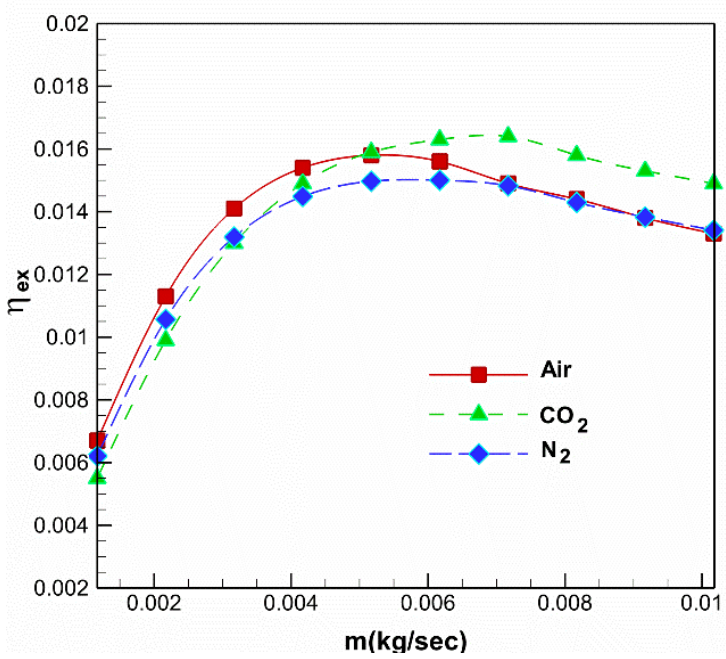

Figure 13. Variation of exergic efficiency with mass flow rate in watt $=600$ for different gases

\section{CONCLUSION}

In this article, two problems are taken into account by conducting thermodynamic and mathematical model for a simple solar air heater. First, effect of the auxiliary thermal element added to air heater in hybrid mode is investigated. Moreover, assuming that air heater is used in food dehydrators, effect of the properties of the gas passing 
through air heater is evaluated by regarding nitrogen and carbon dioxide as neutral gases. The focus is placed on thermal performance of air heater, including output temperature, thermal efficiency, and second law efficiency.

The most significant results include:

- $\quad$ The maximum output temperature and second law efficiency are associated with air heater working with carbon dioxide and the maximum thermal efficiency is related to air heater with working fluid of air.

- Increasing element power added in hybrid mode to solar air heater increases output temperature, thermal efficiency, and second law efficiency.

- Increasing flow rates of fluid in air heater always enhances the thermal efficiency, however, second law efficiency increases with steep slope at first and then it decreases with gentle slope.

- Due to higher outlet temperature and thermal efficiency, carbon dioxide is the best working fluid applying as dehydrators in air heaters in compared to nitrogen and air.

\section{NOMENCLATURE}

\begin{tabular}{|c|c|}
\hline$A$ & Surface area $\left(m^{2}\right)$ \\
\hline$C_{p}$ & Specific heat capacity $(J / K g K)$ \\
\hline $\mathrm{D}$ & Hydraulic diameter(m) \\
\hline$d$ & Differential \\
\hline E & Energy $(W)$ \\
\hline $\mathrm{E}_{\mathrm{x}}$ & Exergy (w) \\
\hline g & Gravity constant $\left(\mathrm{m} / \mathrm{sec}^{2}\right)$ \\
\hline $\mathrm{h}$ & Heat transfer coefficient $\left(W / m^{2} K\right)$ \\
\hline I & Intensity of solar radiation $\left(\mathrm{W} / \mathrm{m}^{2}\right)$ \\
\hline $\mathrm{k}$ & Thermal conductivity $(\mathrm{W} / \mathrm{mK})$ \\
\hline$\dot{m}$ & Mass flow rate $(\mathrm{kg} / \mathrm{sec})$ \\
\hline $\mathrm{Nu}$ & Nusselt number \\
\hline $\mathrm{P}$ & Pressure $(P a)$ \\
\hline $\mathrm{Ra}$ & Rayleigh number \\
\hline $\mathrm{t}$ & Time (sec) \\
\hline $\mathrm{T}$ & Temperature $(K)$ \\
\hline $\mathrm{U}$ & Overall heat transfer coeff. $\left(\mathrm{W} / \mathrm{m}^{2} \mathrm{~K}\right)$ \\
\hline $\mathrm{V}$ & Velocity $(\mathrm{m} / \mathrm{sec})$ \\
\hline watt & Element energy $(\mathrm{W})$ \\
\hline $\mathrm{y}$ & $\mathrm{Y}$ axis \\
\hline \multicolumn{2}{|c|}{ Greek symbols } \\
\hline$\alpha$ & absorptivity \\
\hline$\beta$ & Volume expansion coefficient \\
\hline$\varepsilon$ & Emissivity \\
\hline$\eta$ & Efficiency \\
\hline$\vartheta$ & Cinematic viscosity $\left(\mathrm{m}^{2} / \mathrm{s}\right)$ \\
\hline$\sigma$ & Stefan Boltzmann's constant $\left(\mathrm{W} / \mathrm{m}^{2} \mathrm{~K}^{4}\right)$ \\
\hline$\tau$ & Transmissivity \\
\hline$\Delta$ & Difference \\
\hline \multicolumn{2}{|c|}{ Subscript } \\
\hline $\mathrm{a}$ & Ambient \\
\hline $\mathrm{b}$ & Absorber plate \\
\hline $\mathrm{cbf}$ & Convection of absorber to fluid \\
\hline $\operatorname{cbg}$ & Convection of absorber to glass \\
\hline $\begin{array}{l}\text { cgf } \\
\text { elem }\end{array}$ & $\begin{array}{l}\text { Convection of glass to fluid } \\
\text { element }\end{array}$ \\
\hline
\end{tabular}


Journal of Thermal Engineering, Research Article, Vol. 7, No. 4, pp. 715-730, May, 2021

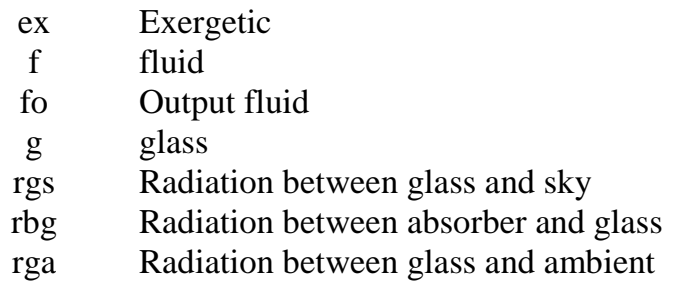

\section{REFERENCES:}

[1] Forson FK, Nazha M A, Rajakaruna H. Experimental and simulation studies on a single pass, double duct solar air heater. Energy conversion and Management 2003; 44(8): 1209-1227. doi: 10.1016/S0196-8904(02)001395.

[2] Aharwal K, Gandhi B, Saini J, Experimental investigation on heat-transfer enhancement due to a gap in an inclined continuous rib arrangement in a rectangular duct of solar air heater. Renewable energy 2008; 33(4): 585-596. doi:10.1016/j.renene.2007.03.023.

[3] Saxena A, El-Sebaii A, A thermodynamic review of solar air heaters. Renewable and Sustainable Energy Reviews 2015; 43: 863-890. doi:10.1016 /j.rser.2014.11.059.

[4] Singh S, Dhiman P. Exergoeconomic analysis of recyclic packed bed solar air heater-sustained air heating system for buildings. Journal of Energy Storage 2016; 5(3): 33-47. doi: 10.1016/j.est.2015.11.008.

[5] Choudhury C, Chauhan P, Garg H, Garg S. Cost - benefit ratio of triple pass solar air heaters. Energy conversion and management 1996; 37(1): 95-116. doi: 10.1016/0196-8904(95)00017-8.

[6] Garg H, Adhikari R. Conventional hybrid photovoltaic/thermal (PV/T (air heating collectors: steady-state simulation. Renewable Energy1997; 11(3): 363-385. doi: 10.1016/S0960-1481(97)00007-4.

[7] Gawande V B, Dhoble A, Zodpe D, Chamoli S. Analytical approach for evaluation of thermo hydraulic performance of roughened solar air heater. Case Studies in Thermal Engineering 2016; 8: 19-31. doi: 10.1016/j.csite.2016.03.003.

[8] Jin D, Zhang M, Wang P, Xu S. Numerical investigation of heat transfer and fluid flow in a solar air heater duct with multi V-shaped ribs on the absorber plate. Energy 2015; 89: 178-190. doi: 10.1016/j.energy.2015.07.069.

[9] Amori KE, Abd-AlRaheem MA. Field study of various air based photovoltaic/thermal hybrid solar collectors. Renewable Energy 2014; 63: 402-414. doi: 10.1016/j.renene.2013.09.047.

[10] Jani D, Mishra M, Sahoo P. Performance prediction of solid desiccant-Vapor compression hybrid airconditioning system using artificial neural network. Energy 2016;103: 618-629. doi: 10.1016/j.energy.2016.03.014.

[11] Siddiqui F R, Elminshawy N A, Addas M F. Design and performance improvement of a solar desalination system by using solar air heater: Experimental and theoretical approach. Desalination 2016; 399: 78-87. doi: 10.1016/j.desal.2016.08.015.

[12] Rajaseenivasan T, Prasanth S R, Antony M S, Srithar K. Experimental investigation on the performance of an impinging jet solar air heater. Alexandria Engineering Journal 2017; 56, (1): 3-69. doi: 10.1016/j.aej.2016.09.004. [13] Michael J J, Selvarasan I, Goic R. Fabrication, experimental study and testing of a novel photovoltaic module for photovoltaic thermal applications. Renewable Energy 2016; 90: 95-104. doi: 10.1016/j.renene.2015.12.064.

[14] Manzolini G, Colombo L P, Romare S, Fustinoni D. Tiles as solar air heater to support a heat pump for residential air conditioning. Applied Thermal Engineering 2016; 102: 1412-1421. doi: 10.1016/j.applthermaleng.2016.03.009.

[15] Wadhawan A, Dhoble A, Gawande V. Analysis of the effects of use of thermal energy storage device (TESD) in solar air heater. Alexandria Engineering Journal 2018; 57(3): 1173-1183. doi: 10.1016/j.aej.2017.03.016.

[16] Fan W, Kokogiannakis G, Ma Z, Cooper P. Development of a dynamic model for a hybrid photovoltaic thermal collector-Solar air heater with fins. Renewable Energy 2017; 101: 816-834. doi: 10.1016/j.renene.2016.09.039.

[17] Hakim II, Putra N, Gunawan Y. Experimental study for heat pipe applications on low enthalpy geothermal energy utilization for agricultural products dryers. Journal of Advanced Research in Fluid Mechanics and Thermal Sciences 2019; 56(1): 68-77.

[18] Heydari A, Mesgarpour M. Experimental analysis and numerical modeling of solar air heater with helical flow path. Solar Energy 2018;162: 278-288. doi: 10.1016/j.solener.2018.01.030.

[19] Raj AK, Srinivas M, Jayaraj S, A cost-effective method to improve the performance of solar air heaters using discrete macro-encapsulated PCM capsules for drying applications. Applied Thermal Engineering 2019;146: 910-920. doi: 10.1016/j.applthermaleng.2018.10.055. 
[20] Sreekumar A. Techno-economic analysis of a roof-integrated solar air heating system for drying fruit and vegetables. Energy Conversion and Management 2010; 51(11): 2230-2238. doi: 10.1016/j.enconman.2010.03.017. [21] Yıldırım C, Tümen Özdil N F. Theoretical Investigation of a Solar Air Heater Roughened by Ribs and Grooves. Journal of Thermal Engineering 2018; 4(1): 1702-1712. doi: 10.18186/ JTE. 365713.

[22] Singh J, Singh R, Bhushan B. Thermo-Hydraulic Performance of Solar Air Heater Duct having Triangular Protrusions as Roughness Geometry. Journal of Thermal Engineering, Special Issue 2: Energy Systems and Developments 2015; 1(7): 607-620. doi: 10.18186/JTE. 01332.

[23] El-Sebaii A, Al-Snani H. Effect of selective coating on thermal performance of flat plate solar air heaters. Energy 2010; 35(4): 1820-1828. doi: 10.1016/j.energy.2009.12.037.

[24] Kurtbas I, Durmuş A. Efficiency and exergy analysis of a new solar air heater. Renewable Energy 2004; 29(9): 1489-1501. doi: 10.1016/j.renene.2004.01.006.

[25] Sahu MK, Prasad RK. Exergy based performance evaluation of solar air heater with arc-shaped wire roughened absorber plate. Renewable Energy 2016; 96: 233-243. doi: 10.1016/j.renene.2016.04.083.

[26] Aboul-Enein S, El-Sebaii A, Ramadan M, El-Gohary H. Parametric study of a solar air heater with and without thermal storage for solar drying applications. Renewable Energy 2000; 21( 3): 505-522. doi: 10.1016/S09601481(00)00092-6.

[27] Cengel YA, Boles MA. Thermodynamics An Engineering Approach. United States, McGraw-Hill Education, 8th edition, ISBN13 9780073398174. 